\title{
Sistem Jaminan Mutu dan Prediksi pada Rantai Pasok Ikan dari Perikanan Sungai
}

\author{
Muhammad Rivani Ibrahim ${ }^{\mathrm{a}, *}$ dan Mustafid ${ }^{\mathrm{b}}$ \\ ${ }^{a}$ Program Studi Magister Sistem Infromasi, Universitas Diponegoro \\ bepartemen Statistika, Fakultas Sains dan Matematika, Universitas Diponegoro
}

Naskah Diterima : 29 Maret 2021; Diterima Publikasi : 28 Mei 2021

DOI: 10.21456/vol11iss1pp43-50

\begin{abstract}
The supply chain system with quality assurance and fish prediction has important role for producers and consumers regarding the need for fresh fish to be consumed in certain size. The research aims to design quality assurance and predictive model for the fish supply chain system so that it is always available to consumers. The Fuzzy Tsukamoto method approach is used to design prediction model for required fish based on the fish provided by fishermen, and Fuzzy Mamdani approach is used to design model for quality assurance of fish needs that consumers need every week and month. This supply chain system is designed with upstream fishermen and fish sellers and as downstream fish retailers and fish consumers, while data analysis uses quantitative data sourced from fishermen and fish sellers and fish consumers. The prediction system and fish quality assurance provide output as a material for decision making in order to obtain information for agents and consumers that they can provide and supply fish as needed. A case study was conducted on the river fishery sector in Kota Bangun District.
\end{abstract}

Keywords : Rantai pasok Systems; Prediction Model; Quality Assurance; Fuzzy Tsukamoto; Fuzzy Mamdani

\begin{abstract}
Abstrak
Sistem rantai pasok dengan jaminan mutu dan prediksi ikan mempunyai peranan penting bagi produsen dan konsumen terhadap kebutuhan ikan segar untuk dikonsumsi dengan ukuran tertentu. Penelitian ini bertujuan mendesain model jaminan mutu dan prediksi ketersediaan dan kebutuhan ikan pada sistem rantai pasok ikan agar selalu tersedia untuk konsumen. Pendekatan metode Fuzzy Tsukamoto digunakan untuk membuat model prediksi ketersediaan ikan berdasarakan ikan yang disediakan oleh nelayan, dan pendekatan Fuzzy Mamdani digunakan untuk membuat model jaminan mutu kebutuhan ikan yang diperlukan konsumen setiap minggu dan bulannya. Sistem rantai pasok ini didesain dengan upstream para nelayan dan sebagai downstream adalah ritel ikan dan konsumen ikan. Data yang digunakan adalah data jumlah data kualitas ikan yang bersumber dari nelayan dan bagian penjual ikan serta konsumen ikan. Sistem prediksi dan jaminan mutu ikan memberikan keluaran sebagai bahan pengambilan keputusan agar didapatkan informasi bagi agen dan konsumen sehingga dapat menyediakan dan menyuplai ikan sebagaimana yang dibutuhkan. Studi kasus dilakukan pada skctor perikanan sungai di Kecamatan Kota Bangun.
\end{abstract}

Kata kunci : Sistem Rantai Pasok; Model Prediksi; Jaminan Mutu; Fuzzy Tsukamoto; Fuzzy Mamdani

\section{Pendahuluan}

Sistem jaminan mutu pada rantai pasok ikan memiliki peran penting untuk memenuhi kebutuhan ikan segar terhadap konsumen ( $\mathrm{Hu}$ et al., 2019). Permintaan ikan di agen Kecamatan Kota Banguns cukup tinggi sekitar $1000 \mathrm{~kg}$ atau lebih perbulannya. Permintaan ikan bukan hanya berasal dari Kecamatan Kota Bangun tetapi juga berasal dari luar Kecamatan Kota Bangun. Tingginya permintaan ikan segar perlu disikapi dengan pengelolaan manajamen rantai pasok yang tepat, selain itu permintaan ikan segar yang berbeda dari konsumen memiliki jaminan mutu yang berbeda juga. Saat ini agen di Kecamatan Kota Bangun memerlukan sistem rantai pasok yang tepat dalam memenuhi keinginan retail dan konsumen
Perikanan di Kecamatan Kota Bangun adalah ikan mujair, ikan emas, ikan patin dan ikan lele. Pada penelitian ini fokus untuk membuat sistem prediksi berdasarkan jaminan mutu pada ikan mujair (nila) (Wang dan Yue, 2017). Terdapat beberapa metode dalam sistem prediksi, antara lain menggunakan logika Fuzzy. Logika Fuzzy dapat digunakan dalam model memprediksi dan jaminan mutu pada djumlah kebutuhan yang akan diperlukan, dengan menggunakan data kebutuhan sebelumnya sehingga dapat meminimalisir kerugian dan stok yang melimpah. Hal tersebut dikarenakan logika fuzzy merupakan logika yang menggambarkan ketidakpatian dan dapat mentoleransi data yang tidak tepat. Pada logika fuzzy terdapat beberapa metode, diantaranya adalah metode fuzzy Mamdani dan

\footnotetext{
*) Penulis korespondensi: rvn.ilkom@gmail.com
} 
Tsukamoto. Perbedaan mendasar dari kedua metode tersebut adalah pada tahapan-tahapan, yaitu tahapan agregasi dan defuzzifikai.

Desain sistem rantai pasok menggunakan model prediksi dengan metode Fuzzy Tsukamoto dan jaminan mutu menggunakan Fuzzy Mamdani. Fuzzy Tsukamoto digunakan untuk menentukan ukuran ikan yang tersedia dalam sebulan kedepan, di mana paramaternya memperhatikan jaminan mutu ikan. Fuzzy Mamdani digunakan untuk menentukan kualitas mutu ikan yang disediakan oleh nelayan yang akan dibeli oleh agen. Fuzzy Mamdani juga digunakan untuk menentukan ukuran dan berat ikan setiap hari, minggu dan bulannya yang dibutuhkan konsumen sehingga ikan selalu tersedia dan tidak berlebihan (Omomule et al., 2020)

Penelitian ini bertujuan mendesain sistem rantai pasok dengan model jaminan mutu dan prediksi berdasarkan data kebutuhan konsumen. Dengan sistem rantai pasok tersebut dapat dilakukan pengelolaan, distribusi dan menjaga kualitas ikan, dan memberikan informasi ikan segar yang selalu tersedia dari agen atau ritel yang memerlukan ikan.

\section{Kerangka Teori}

\subsection{Sistem Jaminan Mutu dan Prediksi ikan}

Sistem jaminan mutu dan pridiksi ketersediaan dan kebutuhan ikan divisualisakan dalam sistem rantai pasok, seperti pada Gambar 1.

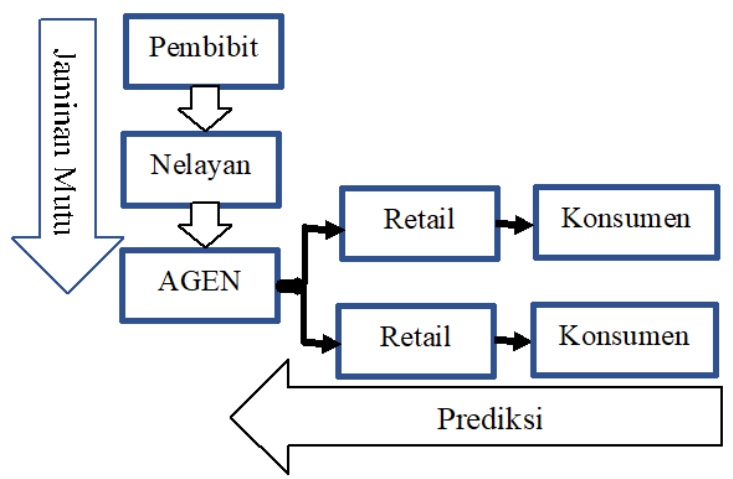

Gambar 1. Sistem jaminan mutu dan prediksi ikan

Sistem jaminan mutu dan prediksi ikan pada Gambar 1 menggunakan database pada Agen sebagai pusat data untuk semua data atau informasi yang digunakan dalam rantai pasok. Sistem jaminan mutu rantai pasok didesain dengan upstream para nelayan dan sebagai downstream adalah ritel ikan dan konsumen ikan.

\section{a. Nelayan}

Pada upstream rantai pasok, para nelayan berfungsi sebagai pensuplai ikan ke Agen. Untuk keperluan tersebut, maka diperlukan informasi ikan apa saja yang diperlukan dalam 1 bulan kedepan agar nantinya saat panen ikan dapat dijual dengan harga yang sesuai dan tidak membuat ikan melimpah, sehingga tetap menjaga ketersediaan ikan, kualitas ikan dan harga ikan yang nantinya dikirim ke agen. Pada model jaminan mutu pada sistem rantai pasok dilakukan perhitungan untuk menentukan mutu ikan sebagai dasar jaminan mutu berdasarkan ukuran berat dan tingkat luka ikan, prediksi ketersediaan dan prediksi kebutuhan ikan berdasarkan kebutuan ikan dari konsumen.

\section{b. Agen}

Pada proses ini agen melakukan persiapan persediaan ikan agar selalu tersedia untuk retail dan konsumen berdasarkan data dari pensuplai ikan (nelayan dan penjual ikan) dan permintaan atau kebutuhan ikan dari konsumen. Dengan demikian, Agen perlu informasi seberapa banyak nelayan yang memelihara ikan yang dibutuhkan agar pada proses penjualan ikan tidak melimpah dan dapat mempertahankan harga yang baik untuk nelayan dan retail.

\section{c. Retail}

Pada dounstrem rantai pasok, retail menjual dan memasarkan ikan ke konsumen. Pada proses ini retail juga perlu diberikan informasi tentang ikan yang ada di agen sehingga memudahkan retail dalam mengakomodasi kebutuhan masyarakat sebagai konsumen. Pada tahap ini juga, retail akan memberikan informasi ikan apa saja yang dibutuhkan oleh konseumen kepada Agen.

Sistem jaminan mutu ikan pada rantai pasok pada Gambar 1 didesain menggunakan data kebutuhan ikan segar pelanggan atau konsumen berdasarkan beberapa kriteria yang diinginkan oleh konsumen rumah tangga dan konsumen warung makan, seperti diberikan dilihat pada Tabel 1. Kriteria konsumsi ikan segar sebagai standar pada jaminan mutu ikan segar diperoleh dari hasil warancara dengan agen ikan segar yang berhubungan dengan konsumen di Kecamatan Kota Bangun.

Tabel 1. Kriteria jaminan mutu ikan nila

\begin{tabular}{cll}
\hline No & \multicolumn{1}{c}{ Jenis } & \multicolumn{1}{c}{ Kriteria } \\
\hline 1 & $\begin{array}{l}\text { Ikan Segar untuk } \\
\text { Konsumen Rumah } \\
\text { Tangga }\end{array}$ & $\begin{array}{l}\text { a. Tidak ada luka } \\
\text { b. Ukuran } \geq 3 \text { ons } \\
\text { c. Berbau segar (masih } \\
\text { hidup) }\end{array}$ \\
& & $\begin{array}{l}\text { a. Ukuran 2.5-4 ons } \\
2\end{array}$ \\
& $\begin{array}{l}\text { Ikan Segar untuk } \\
\text { Konsumen Usaha } \\
\text { Kuliner }\end{array}$ & $\begin{array}{l}\text { b. Berbau segar (masih } \\
\text { hidup) }\end{array}$ \\
\hline
\end{tabular}

Kriteria jaminan mutu ikan pada Tabel 1 digunakan sebagai standar agen dalam membuat ketersediaan ikan segar ke nelayan. Pada sistem ini nelayan akan melakukan input kondisi ikan sebelum agen membeli ikan ke nelayan setempat.

Sistem prediksi ikan segar didesain berdasarkan kebutuhan pelanggan atau konsumen. Sistem prediksi menggunakan 2 model pendekatan, pertama prediksi kebutuhan ikan setiap bulannya dan kedua prediksi ketersediaan atau stok ikan yang dapat disediakan 
setiap bulannya. Prediksi stok ikan yang dapat disediakan memiliki kriteria dengan memperhatikan jumlah bibit, ukuran keramba, banyak keramba dan pakan ikan. Prediksi kebutuhan ikan setiap bulannya memiliki kriteria ukuran ikan, penjualan ikan, pembelian ikan dan persediaan ikan.

\subsection{Himpunan Fuzzy}

Logika Fuzzy merupakan generalisasi dari logika klasik yang hanya memiliki dua nilai keanggotaan, yaitu 0 dan 1. Metodologi logika fuzzy memiliki kemampuan dalam merepresentasikan dan menangani konsep atau pengetahuan yang terhadap data yang abu-abu atau tidak jelas untuk dibedakan. Berdasarkan Tabel 2, untuk jaminan mutu ikan, variabel mutu ikan dikategorikan kedalam 3 variabel, yaitu variabel Rendah, Sedang, dan Tinggi, dengan klasifikasi sebagai berikut:

$$
\begin{array}{lr}
\text { Rendah } & \text { mutu }<40 \% \\
\text { Sedang } & 40 \leq \text { mutu } \leq 65 \% \\
\text { Tinggi } & \text { mutu }>65 \%
\end{array}
$$

Demikian juga untuk ketersediaan seperti diberikan pada Tabel 3, klasifikasi ketersediaan dikategorikan menjadi 3 variabel, yaitu Rendah, Sedang, dan Tinggi, dengan klasifikasi sebagai berikut:

$$
\begin{array}{lr}
\text { Rendah } & \text { Kategori }<40 \% \\
\text { Sedang } & 40 \leq \text { Kategori } \leq 65 \% \\
\text { Tinggi } & \text { Kategori }>65 \%
\end{array}
$$

Pendekatan himpunan fuzzy ini menggunakan data yang bersifat kontinyu. Fungsi keanggotaan merupakan kurva yang memetakan titik-titik input data (sumbu $\mathrm{x}$ ) kepada nilai keanggotaan yang mempunyai interval 0 sampai 1 atau dari $0 \%$ sampai dengan $100 \%$.

Tiga pendekatan fungsi fuzzy yang akan digunakan untuk memperoleh nilai keanggotaan pada penelitian ini, yaitu pendekatan linear naik dan kurva segitiga (Mohammad et al., 2015). Metode pendekatan dengan representative kurva linear naik diberikan pada Gambar 2.

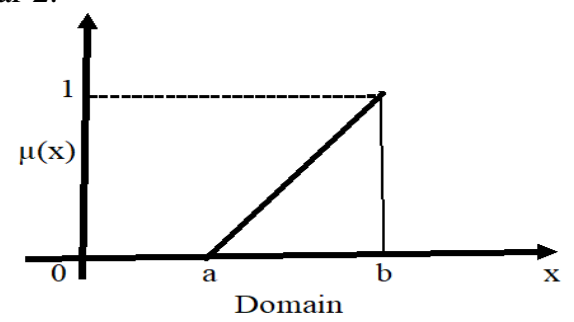

Gambar 2. Representasi kurva linear naik

Fungsi keanggotaan dari Gambar 2, dapat diberikan sebagi berikut:

$$
\mu(\mathrm{x})=\left\{\begin{array}{cc}
0 ; x<a \\
\frac{x-a}{b-a} \quad ; a \leq x \leq b \\
1 ; x>b
\end{array}\right.
$$

Himpunan fuzzy dengan kurva linear naik memiliki domain $(-\infty, \infty)$ dan terbagi menjadi tiga interval yaitu $[0, a),[a, b]$ dan $(b, \infty)$.

Untuk metode pendekatan dengan representative kurva segitiga diberikan pada Gambar 3.

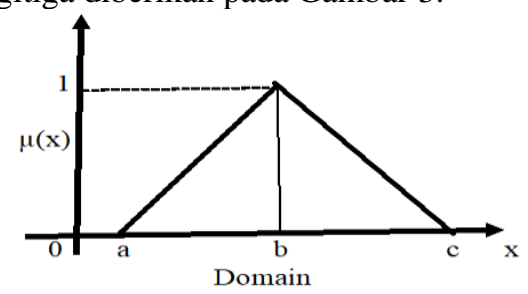

Gambar 3. Representasi kurva segitiga

Fungsi keanggotaan dari Gambar 3, dapat diberikan sebagi berikut:

$$
\mu(\mathrm{x})= \begin{cases}\frac{x-a}{b-a} & ; \quad x \leq x \leq b \\ \frac{c-x}{c-b} & ; b<x \leq c \\ 1 ; x>c\end{cases}
$$

Himpunan fuzzy dengan kurva linear segitiga memiliki domain $(-\infty, \infty)$ dan terbagi menjadi empat interval yaitu $[0, a),[a, b],(b, c]$ dan $(c, \infty)$.

\subsection{Fuzzy Metode Mamdani}

a. Himpunan Fuzzy

Langkah awal dalam penggunaan metode fuzzy adalah menentukan himpunan fuzzy untuk mencari derajat keanggotaan dari fungsi ke keanggotaan yang direpresentasikan dengan kurva segitiga. Berdasarkan data dari penyediaan ikan, kategori pada jaminan mutu dikategorikan menjadi 3 bagian (interval), seperti pada Tabel 2.

Tabel 2. Kategori jaminan mutu ikan

\begin{tabular}{cccc}
\hline \multicolumn{2}{c}{ Mutu Ikan } & \multicolumn{2}{c}{ Kategori } \\
\hline \multirow{2}{*}{$\geq 65 \%$} & Bagus & Luka & $\leq 15 \%$ \\
& & Ukuran & $>50 \%$ \\
& & Luka & $>15 \%$ \\
& \multirow{2}{*}{ Sedang } & Ukuran & $\geq 50 \%$ \\
& & Luka & $\geq 40 \%$ \\
& Rendah & Ukuran & $\geq 20 \%$ \\
\hline
\end{tabular}

Variabel untuk model prediksi ketersediaan ikan didefinisikan pada 3 dan 2 himpunan fuzzy yaitu RENDAH, SEDANG, TINGGI, dan RENDAH, TINGGI. Selanjutnya pada model prediksi jumlah ikan menggunakan 3 himpunan, yaitu jumlah bibit, ukuran keramba dan hasil panen dan 2 himpunan yaitu jumlah keramba dan pemilihan. Pada Tabel 3 menjelaskan kategori jaminan mutu ikan sebagai variabel yang dibuat berdasarkan kriteria nelayan. Fuzzy memiliki interval derajat keanggotaan. 
Tabel 3. Kategori ketersediaan ikan

\begin{tabular}{cccc}
\hline \multicolumn{2}{c}{ Kategori } & \multicolumn{2}{c}{ Ukuran } \\
\hline \multirow{3}{*}{$\geq 60 \%$} & Tinggi & $35 \%$ & $2-3$ \\
& & $20 \%$ & $3-5$ \\
& & $5 \%$ & $\geq 5$ \\
\multirow{2}{*}{$<40 \%$} & Sedang & $30 \%$ & $2-3$ \\
& & $10 \%$ & $3-5$ \\
\hline
\end{tabular}

b. Fungsi Implikasi

Fungsi implikasi yang digunakan dalam proses ini adalah fungsi MIN, yaitu dengan mengambil derajat keanggotaan minimum dari variabel input sebagai outputnya (Mohammad et al., 2015; Mojtaba, 2016) Berdasarkan aturan-aturan yang sesuai dengan fungsi implikasi. Tahap pertama pada jaminan mutu ikan memiliki 9 aturan. Contoh dari sembilan aturan adalah "Jika luka ikan SEDIKIT dan Ukuran ikan KURANG maka Kualitas ikan SEDANG”. Untuk tahap kedua, yaitu pada prediksi ikan memiliki 65 aturan. Contoh aturan yang pertama adalah "Jika jumlah bibit SEDIKIT dan ukuran keramba KURANG dan jumlah keramba KURANG dan makan KURANG dan pemilihan KURANG maka hasil panen RENDAH'.

\section{c. Komposisi Aturan}

Komposisi aturan diperoleh dari nilai implikasi yang telah dicari, kemudian nilai tersebut digunakan untuk memodifikasi daerah fuzzy. Komposisi aturan merupakan kesimpulan secara keseluruhan dengan mengambil tingkat keanggotaan maksimum dari tiap konsekuen aplikasi fungsi implikasi dengan menggabungkan dari semua kesimpulan masingmasing aturan $\mathrm{z}_{\mathrm{j}}$, sehingga didapat daerah solusi fuzzy. Nilai pada komposisi aturan didapat dengan persamaan (Yang dan Yanyan, 2014);

$$
z=\text { (nilai aturan } * \mu\left(z_{j}\right)+\text { nilai aturan }
$$

\section{d. Defuzzyfikasi}

Deffuzifikasi digunakan untuk mengubah himpunan fuzzy menjadi bilangan riil. Input dari proses penegasan ini adalah himpunan fuzzy yang dibangun berdasarkan komposisi aturan-aturan fuzzy seperti diberikan pada Tabel 1. Sedangkan output yang dihasilkan merupakan standar mutu ikan sebagai acuan untuk menentukan mutu ikan dalam penyediaan ikan dari nelayan. Defuzzyfikasi menggunakan persamaan:

$$
Z=\frac{\Sigma_{j=i}^{n} z_{j} \mu\left(z_{j}\right)}{\Sigma_{j=i}^{n} \mu\left(z_{j}\right.}
$$

\subsection{Fuzzy Metode Tsukamoto}

Fuzzy Tsukamoto digunakan sebagai metode untuk memprediksi kebutuhan ikan berdasarkan data dari Kecamatan Kota Bangun (Omomule et al., 2020). Pada dasarnya, metode Tsukamoto mengaplikasikan penalaran monoton pada setiap aturannya. Pada penelitian ini digunakan beberapa aturan dalam prediksi kebutuhan ikan nila di Kecamatan Kota Bangun. Terdapat 5 aturan yang ada pada penelitian ini sehingga dalam inferensinya, metode Tsukamoto menggunakan beberapa tahapan (Wahyuni et al., 2016; Tri Hastono et al., 2017):

a. Pembentukan basis pengetahuan Fuzzy (Rule dalam bentuk IF penjualan turun AND persediaan banyak THEN pembelian berkurang (Tundo dan Enny, 2018)

b. Mesin inferensi menggunakan fungsi implikasi MIN untuk mendapatkan nilai $\alpha$ predikat tiap - tiap rule $\left(\alpha_{1}, \alpha_{2}, \alpha_{3}, \ldots . . \alpha_{n}\right)$. Kemudian masing-masing $\alpha$-predikat ini digunakan untuk menghitung keluaran hasil inferensi secara tegas (crisp) masing-masing rule $\left(\mathrm{z}_{1}, \mathrm{z}_{2}, \mathrm{z}_{3}, \ldots ., \mathrm{z}_{\mathrm{n}}\right)$.

c. Tahap terakhir adalah menghitung defuzzyfikasi yang menghasilkan keperluan jumlah ikan pada bulan berikutnya dengan menggunakan Persamaan 2.

Fuzzyfikasi menentukan apa saja aturan yang digunakan, misalkan pada aspek penjualan, pembelian dan kebutuhan. Data dari penjualan, persediaan, dan pembelian akan dibuat dalam bentuk batasan faktor yang bertujuan untuk menentukan nilai maksimum dan nilai minimum dari setiap penjualan, persediaan dan pembelian ikan nila di Kecamatan Kota Bangun. Nilai ini merupakan hasil rata-rata dari bulan April sampai Oktober 2020. Data batasan faktor dapat dilihat pada Tabel 4. Setelah menentukan nilai maksimum dan minimum dari penjualan (PJG), persediaan (PSD) dan pembelian (PBL), selanjutnya menetukan nilai maksimum dan nilai minimum dari Agen seperti dapat dilihat pada Tabel 5.

Tabel 4. Faktor prediksi kebutuhan ikan

\begin{tabular}{cccccc}
\hline \multirow{2}{*}{$\begin{array}{c}\text { Nama } \\
\text { Ikan }\end{array}$} & $\begin{array}{c}\text { Ukuran } \\
\text { (ons) }\end{array}$ & Batas & \multicolumn{3}{c}{ Faktor } \\
\cline { 4 - 6 } & & PJG & $\begin{array}{c}\text { PSD } \\
(\mathrm{kg})\end{array}$ & $\begin{array}{c}\text { PBL } \\
(\mathrm{kg})\end{array}$ \\
\hline & $2-3$ & Max & 43,2 & 227,7 & 109,3 \\
& & Min & 29,9 & 107,7 & 0,0 \\
Ikan & $3-5$ & Max & 110,5 & 307,2 & 164,0 \\
Nila & & Min & 86,2 & 196,1 & 28,2 \\
& & Max & 37,7 & 273,6 & 85,4 \\
& $\geq 5$ & Min & 26,4 & 151,4 & 0,0 \\
\hline
\end{tabular}

Tabel 5. Nilai maksimum dan minimum dalam prediksi

\begin{tabular}{cccc}
$\begin{array}{c}\text { Nama } \\
\text { Ikan }\end{array}$ & $\begin{array}{c}\text { Ukuran } \\
\text { (ons) }\end{array}$ & Batas & Prediksi \\
\hline \multirow{4}{*}{ Ikan Nila } & $2-2,5$ & Max & 50,0 \\
& & Min & 30,0 \\
& $3-5$ & Max & 120,0 \\
& & Min & 90,0 \\
& & Max & 40,0 \\
\hline
\end{tabular}




\section{Metode}

Penelitian ini mendesain dan menerapkan rantai pasok ikan segar, dengan upstream nelayan sebagai pensuplai ikan dan downstream adalah ritel dan konsumen ikan. Sedangkan Agen yang melakukan pengumpulkan ikan dari nelayan dengan memberlakukan jaminan mutu dan prediksi berapa kebutuhan ikan bagi konsumen. Data yang digunakan dalam sistem ini adalah data dari hasil penjualan ritel, dan persediaan ikan di tempat agen, dan suplai ikan dari nelayan. Pendataan dilakukan dari bulan April Oktober 2020.

Nilai dari sistem prediksi kebutuhan ikan akan dibandingkan dengan penjualan ikan dengan data yang diambil pada bulan November 2020. Nelayan sebagai pensuplai ikan pada sistem ini menggunakan sebanyak 20 nelayan yang ada di Kecamatan Kota Bangun. Pada proses ini dibuat model dan sistem prediksi ketersediaan stok ikan dengan pendekatan menggunakan metode Fuzzy Mamdani, sistem dibuat dengan mengumpulkan informasi dari nelayan berupa banyaknya nelayan yang memelihara ikan nila. Data Nelayan yang diambil antara lain berupa ukuran keramba, jumlahnya, kondisi ikan. Pada penelitian ini data nelayan yang digunakan sebanyak 20 data nelayan yang ada di Kecamatan Kota Bangun.

Pada tahap agen juga dibangun sistem prediksi kebutuhan ikan nila berdasarkan data penjualan, pembelian dan penyimpanan ikan nila di tempat agen. Pada model ini menggunakan pendekatan dengan metode Fuzzy Tsukamoto. Selanjutnya untuk validasi model menggunakan nilai Absolute Percentage Error (MAPE) dengan membandingkan nilai prediksi dan nilai aktual:

$$
\mathrm{MAPE}=\frac{1}{n} \sum_{t=1}^{n} \frac{\left|Y_{t}-F_{t}\right|}{Y_{t}}
$$

dengan $Y_{t}$ adalah data aktual dan $F_{t}$ adalah data hasil prediksi. Nilai MAPE dapat diinterpretasikan ke dalam 4 kategori yaitu: $<10 \%=$ sangat akurat, $(10-$ $20) \%=$ baik, $(20-50) \%=$ wajar dan $>50 \%=$ tidak akurat (Yang dan Yanyan, 2014).

Semakin kecil nilai MAPE maka semakin kecil kesalahan hasil pendugaan, sebaliknya semakin besar nilai MAPE maka semakin besar kesalahan hasil pendugaan hasil prediksi. Hasil suatu metode pendugaan mempunyai kemampuan peramalan sangat baik jika nilai MAPE $<10 \%$ dan mempunyai kemampuan pendugaan baik jika nilai MAPE diantara $10 \%$ dan $20 \%$.

\section{Hasil dan Pembahasan}

\subsection{Jaminan Mutu Ikan}

Jaminann mutu ikan didesain berdasarkan informasi standar jaminan mutu berdasarkan kebutuhan dan ketersediaan serta mutu ikan yang terdapat di Kecamatan Kota Bangun, sehingga dapat menjaga jaminan mutu konsumen. Jumlah ketersediaan ikan digunakan untuk menentukan nilai fuzzykasi dengan menggunakan 3 variabel pada kategori dan ukuran ikan seperti diberikan pada Tabel 3, yaitu "RENDAH, SEDANG, TINGGI" sebagai kategori dan ukuran ikan sebagai dasar pada penentuan standar jaminan mutu ikan. Berdasarkan data permintaan maksimum dan minimum, maka fungsi keanggotaan memakai rumus representasi linear naik. Menggunakan data ketersediaan dan ukuran ukan, dilakukan perhitungan fuzzyfikasi luka ikan dan ukuran ikan yang hasilnya diberikan pada Tabel 6 dan Tabel 7.

Tabel 6. Fuzzyfikasi luka ikan

\begin{tabular}{cccc}
\multicolumn{4}{c}{ Luka Ikan } \\
\hline Nama & Rendah & Sedang & Bagus \\
\hline NKB1 & 0,0 & 0,7 & 0,0 \\
NKB2 & 0,0 & 0,0 & 1,0 \\
NKB3 & 0,0 & 0,0 & 1,0 \\
NKB4 & 0,0 & 0,0 & 1,0 \\
NKB5 & 0,7 & 0,3 & 0,0 \\
$\ldots \ldots \ldots$. & $\ldots \ldots \ldots \ldots$ & $\ldots \ldots \ldots \ldots$ & $\ldots \ldots \ldots \ldots$ \\
NKB20 & 1,0 & 0,0 & 0,0 \\
\hline
\end{tabular}

Tabel 7. Fuzzyfikasi ukuran ikan

\begin{tabular}{cccc}
\hline \multicolumn{4}{c}{ Luka Ikan } \\
\hline Nama & Rendah & Sedang & Bagus \\
\hline NKB1 & 0,0 & 0,0 & 0,5 \\
NKB2 & 1,0 & 0,0 & 0,0 \\
NKB3 & 0,0 & 0,0 & 0,9 \\
NKB4 & 1,0 & 0,0 & 0,0 \\
NKB5 & 0,0 & 0,0 & 0,9 \\
$\ldots \ldots \ldots \ldots$ & $\ldots \ldots \ldots \ldots$ & $\ldots \ldots \ldots \ldots$ & $\ldots \ldots \ldots$ \\
NKB20 & 0,3 & 0,5 & 0,0 \\
\hline
\end{tabular}

Dari hasil nilai Fuzzifikasi ditentukan nilai min berdasarkan aturan pada fungsi implikasi Misalkan aturan yang menyebutkan bahwa "Jika luka ikan SEDIKIT dan Ukuran ikan KURANG maka Kualitas ikan SEDANG”. Penelitian ini menggunakan 9 aturan, yaitu: $Z_{1}, Z_{2}, Z_{3}, . ., Z_{9}$. Berdasarkan hasil nilai 9 aturan tersebut digunakan untuk menentukan nilai weighted average sebagai mutu ikan (Tabel 8).

Tabel 8. Nilai Weighted Average dan defuzzyfikasi

\begin{tabular}{cccccccc}
\hline & Z1 & Z2 & Z3 & Z4 & $\ldots \ldots \ldots$ & Z9 & Z \\
\hline NKB1 & 40 & 40 & 60 & 20 & $\ldots \ldots \ldots$ & 20 & 59,0 \\
NKB2 & 40 & 40 & 60 & 20 & $\ldots \ldots \ldots$ & 20 & 40,0 \\
NKB3 & 40 & 40 & 60 & 20 & $\ldots \ldots \ldots$ & 38 & 37,9 \\
NKB4 & 40 & 40 & 60 & 20 & $\ldots \ldots \ldots$ & 20 & 40,0 \\
NKB5 & 40 & 40 & 103 & 20 & $\ldots \ldots \ldots$ & 20 & 87,8 \\
$\ldots \ldots \ldots$ &. & $\ldots$. & $\ldots$. & $\ldots$. & $\ldots \ldots \ldots$ & $\ldots$. & \\
NKB20 & 50 & 59 & 60 & 21 & $\ldots \ldots \ldots$ & 20 & 53,2 \\
\hline
\end{tabular}

Pada Tabel 8 menghasilkan nilai prosentasi mutu ikan (Z) sebagai hasil dari weighted average 9 aturan. Misalnya untuk Nelayan Kota Bangun (NKB5) menghasilkan mutu ikan $87,8 \%$. Hal ini menunjukan bahwa dengan mutu tinggi, ikan siap dijual ke agen, karena luka ikan yang sedikit dan ukuran ikan yang banyak. Menggunakan kategori ketersidaan ikan pada 
Tabel 3, menunjukkan bahwa nilai presentase sebesar $87,9 \%$ merupakan mutu ikan yang tinggi.

\subsection{Prediksi Ketersediaan Ikan}

Untuk prediksi ketersiaan ikan menggunakan 65 aturan; $\mathrm{R}_{1}, \mathrm{R}_{2}, \mathrm{Z}_{3}, . ., \mathrm{R}_{66}$. Auran ini digunakan untuk menentukan nilai minimum berdasarkan nilai implikasi dari setiap aturan yang telah dibuat, hasilnya diberina pada Tabel 9.

Tabel 9. Nilai fungsi implikasi

\begin{tabular}{lllllllll}
\hline R1 & R2 & R3 & R4 & R5 & R6 & R7 & $\ldots$ & R66 \\
\hline$\alpha 1$ & $\alpha 2$ & $\alpha 3$ & $\alpha 4$ & $\alpha 5$ & $\alpha 6$ & $\alpha 7$ & $\ldots$ & $\alpha 66$ \\
0,0 & 0,0 & 0,0 & 0,0 & 0,0 & 0,0 & 0,0 & $\ldots$ & 0,0 \\
0,0 & 0,0 & 0,0 & 0,0 & 0,0 & 0,0 & 0,0 & $\ldots$ & 0,0 \\
0,0 & 0,0 & 0,0 & 0,0 & 0,0 & 0,0 & 0,0 & $\ldots$ & 0,0 \\
0,0 & 0,0 & 0,0 & 0,0 & 0,0 & 0,0 & 0,0 & $\ldots$ & 0,0 \\
0,0 & 0,0 & 0,0 & 0,0 & 0,0 & 0,0 & 0,0 & $\ldots$ & 0,0 \\
0,0 & 0,0 & 0,0 & 0,0 & 0,0 & 0,0 & 0,0 & $\ldots$ & 0,5 \\
$\ldots$ & $\ldots$ & $\ldots$ & $\ldots$ & $\ldots$ & $\ldots$ & $\ldots$ & $\ldots$ & $\ldots$ \\
0,0 & 0,0 & 0,0 & 0,0 & 0,0 & 0,0 & 0,0 & $\ldots$ & 0,5 \\
\hline
\end{tabular}

Selanjutnya nilai pada Tabel 9 akan digunakan untuk mencari nilai dari komposisi aturan menggunakan Persamaan 1. Hail nilai komposisi aturan diberikan pada Tabel 10.

Tabel 10. Nilai komposisi aturan

\begin{tabular}{ccccccccc}
\hline $\mathrm{z} 1$ & $\mathrm{z} 2$ & $\mathrm{z} 3$ & $\mathrm{z} 4$ & $\mathrm{z} 5$ & $\mathrm{z6}$ & $\mathrm{z} 7$ & $\ldots$. & $\mathrm{z} 9$ \\
\hline 20 & 40 & 40 & 60 & 20 & 40 & 40 & $\ldots$. & 60 \\
20 & 40 & 40 & 60 & 20 & 40 & 40 & $\ldots$. & 60 \\
20 & 40 & 40 & 60 & 20 & 40 & 40 & $\ldots \ldots$ & 60 \\
20 & 40 & 40 & 60 & 20 & 40 & 40 & $\ldots$. & 60 \\
20 & 40 & 40 & 60 & 20 & 40 & 40 & $\ldots$. & 60 \\
20 & 40 & 40 & 60 & 20 & 40 & 40 & $\ldots$ & 70 \\
$\ldots$ & $\ldots \ldots$ & $\ldots \ldots$ & $\ldots \ldots$ & $\ldots$ & $\ldots$ & $\ldots$ & $\ldots$. & $\ldots$ \\
20 & 40 & 40 & 60 & 20 & 40 & 40 & $\ldots$. & 70 \\
\hline
\end{tabular}

Tahap terakhir menentukan nilai defuzzykasi dengan metode centroid technique. Metode ini mencari centre of gravity (COG) dari aggregate set dengan menggunakan Persamaan 2 dengan aturan kriteria jaminan mutu pada Tabel 1 . Nilai yang telah diperoleh diberikan pada Tabel 11.

Tabel 11. Nilai komposisi aturan

\begin{tabular}{cc}
\hline \multicolumn{2}{c}{ Z (hasil) } \\
\hline NKB 1 & $58,7 \%$ \\
NKB 2 & $60,0 \%$ \\
NKB 3 & $60,0 \%$ \\
NKB 4 & $62,5 \%$ \\
NKB 5 & $47,1 \%$ \\
NKB 50 & $60,0 \%$ \\
\hline
\end{tabular}

Pada Tabel 11 terlihat bahwa Nelayan Kota Bangun (NKB1) menunjukkan ketersediaan ikan yang sedang $(58,7 \%)$, dikarenakan pemberian makan banyak, pemilihan ikan yang banyak, dengan ukuran keramba ang besar, namun menghasilkan hasil panen yang sedang dengan jumlah bibit sedikit dan jumlah keramba sedikit.
Pada NKB2 menunjukkan ketersediaan ikan yang tinggi dikarenakan NKB2, memiliki bibit ikan nila yang banyak, makan yang banyak, pemilihan yang banyak, ukuran keramba yang besar dengan jumlah keramba yang banyak.

Selanjutnya, sebagai contoh perhitungan bahwa Nelayan Kota Bangun (NKB 1) tersedia 5000 bibit ikan nila. Maka hasil panen $58.7 \%$ dari 5000 bibit ikan nila diperoleh:

1. Ukuran ikan $2-3$ ons diperoleh ketersediaan ikan sebesar $30 \%$, yang berarti berarti jumlah ikan sebanyak 1500 ikan nila, atau jumlah ikan tersebut mencapai sekitar $3.750 \mathrm{~kg}$;

2. Ukuran $3-5$ ons sebesar $20 \%$ berarti jumlah ikan nila dengan ukuran 3 - 4 ons sebanyak 1000 ikan nila dengan kira-kira jumlah berat keseluruhan berat $4000 \mathrm{~kg}$;

3. Ukuran $\geq 5$ ons ons sebesar $3 \%$ berarti jumlah ikan nila dengan ukuran $\geq 5$ ons sebanyak 150 ikan nila dengan kira-kira jumlah berat keseluruhan berat $750 \mathrm{~kg}$.

\subsection{Prediksi Kebutuhan Ikan}

Hasil yang didapat berupa informasi prediksi kebutuhan ikan selama 1 bulan pada Kecamatan Kota Bangun, sehingga dapat menjaga ketersediaan stok ikan, menjaga jaminan mutu konsumen dan menjaga harga ikan di pasar.

Nilai yang terdapat pada Tabel 4 dan Tabel 5 digunakan untuk mencari Fuzzyfikasi yang berguna menentukan 3 variabel penentu dengan perhitungan seperti Permintaan (x), terdiri atas 2 himpunan fuzzy, yaitu TURUN dan NAIK. Berdasarkan data permintaan terbesar dan terkecil untuk penjualan (PJG), persediaan (PSD) dan pembelian (PBL), maka fungsi keanggotaan memakai rumus representasi linear naik. Hasil perhitungan Fuzzyfikasi permintaan turun dapat dilihat pada Tabel 12 dan Fuzzyfikasi permintaan naik dapat dilihat pada Tabel 13 Data yang digunakan penjualan selama 1 bulan

Tabel 12. Fuzzyfikasi permintaan turun

\begin{tabular}{ccccc}
\hline Hari Ke- & Ukuran & PJG $(\mathrm{kg})$ & PSD kg) & PBL $(\mathrm{kg})$ \\
\hline \multirow{2}{*}{1} & $2-3$ & 0,7 & 0,3 & 0,0 \\
& $3-5$ & 0,4 & 0,4 & 0,2 \\
& $>5$ & 0,9 & 0,4 & 0,1 \\
& $2-3$ & 0,5 & 0,1 & 0,5 \\
& $3-5$ & 0,0 & 0,0 & 0,6 \\
2 & $>5$ & 0,0 & 0,0 & 0,3 \\
& 0,3 & 0,5 & 0,8 & 0,3 \\
& 0,0 & 0,3 & 1,0 & 0,0 \\
& 0,4 & 0,6 & 0,2 & 0,4 \\
& 0,3 & 0,7 & 0,7 & 0,3 \\
31 & $\ldots \ldots$. & $\ldots \ldots .$. & $\ldots \ldots$ & $\ldots \ldots$ \\
& $2-3$ & 1,0 & 0,4 & 0,3 \\
& $3-5$ & 0,9 & 1,0 & 1,0 \\
& $>5$ & 0,1 & 0,5 & 0,8 \\
\hline
\end{tabular}


$\underline{\text { Tabel 13. Fuzzyfikasi permintaan naik }}$

\begin{tabular}{ccccc}
\hline $\begin{array}{c}\text { Hari } \\
\text { Ke }-\end{array}$ & Ukuran & PJG $(\mathrm{kg})$ & PSD $(\mathrm{kg})$ & PBL $(\mathrm{kg})$ \\
\hline \multirow{2}{*}{1} & 3-Feb & 0,3 & 0,7 & 1,0 \\
& 5-Mar & 0,6 & 0,6 & 0,8 \\
& $>5$ & 0,1 & 0,6 & 0,9 \\
& 3-Feb & 0,5 & 0,9 & 0,5 \\
& $5-\mathrm{Mar}$ & 1,0 & 1,0 & 0,4 \\
& $>5$ & 1,0 & 1,0 & 0,7 \\
2 & $5-\mathrm{Mar}$ & 0,7 & 0,5 & 0,2 \\
& $>5$ & 1,0 & 0,7 & 0,0 \\
& $5-\mathrm{Mar}$ & 0,6 & 0,4 & 0,8 \\
& $>5$ & 0,7 & 0,3 & 0,3 \\
$\ldots \ldots$. & $\ldots \ldots$. & $\ldots \ldots$. & $\ldots \ldots$. & $\ldots \ldots$ \\
& $3-\mathrm{Feb}$ & 0,0 & 0,6 & 0,7 \\
31 & $5-\mathrm{Mar}$ & 0,1 & 0,0 & 0,0 \\
& $>5$ & 0,9 & 0,5 & 0,2 \\
\hline
\end{tabular}

Hasil dari nilai Fuzzifikasi digunakan untuk menentukan nilai min berdasarkan aturan pada fungsi implikasi "IF penjualan turun AND persediaan banyak THEN pembelian berkurang". Pada penelitian ini terdapat 5 aturan dan nilai itu akan digunakan untuk mencari nilai weighted average yang dapat dilihat pada Tabel 14 dan Tabel 15.

Tabel 14. Nilai defuzzyfikasi dari 5 aturan selama 31 hari

\begin{tabular}{ccccccc}
\hline $\begin{array}{c}\text { Hari } \\
\text { Ke }\end{array}$ & Ukuran & z1 & z2 & z3 & z4 & z5 \\
\hline \multirow{3}{*}{1} & 3-Feb & 50,0 & 50,0 & 43,6 & 43,6 & 50,0 \\
& 5-Mar & 114,8 & 114,8 & 102,6 & 109,5 & 114,8 \\
& $>5$ & 39,5 & 29,5 & 39,1 & 39,1 & 39,5 \\
& 3-Feb & 40,4 & 47,8 & 39,6 & 47,8 & 40,4 \\
2 & 5-Mar & 120,0 & 120,0 & 107,1 & 120,0 & 102,9 \\
& $>5$ & 39,6 & 30,0 & 33,4 & 40,0 & 36,6 \\
& 3-Feb & 44,2 & 44,2 & 50,0 & 50,0 & 38,4 \\
& 5-Mar & 109,9 & 109,9 & 115,1 & 115,1 & 106,2 \\
3 & $>5$ & 40,0 & 30,0 & 40,0 & 40,0 & 33,0 \\
& $5-$ Mar & 113,9 & 113,9 & 109,0 & 101,0 & 113,9 \\
& $>5$ & 37,1 & 27,1 & 36,6 & 36,5 & 36,6 \\
$\ldots .$. & $\ldots .$. & $\ldots \ldots$ & $\ldots \ldots$ & $\ldots \ldots$. & $\ldots \ldots$ & $\ldots .$. \\
& $3-F e b$ & 36,9 & 26,9 & 40,0 & 40,0 & 40,0 \\
31 & 5-Mar & 50,0 & 31,3 & 50,0 & 50,0 & 50,0 \\
& $>5$ & 117,1 & 117,1 & 115,5 & 115,5 & 103,8 \\
\hline
\end{tabular}

Tabel 15. Nilai Weighted Average Z dan MAPE

\begin{tabular}{cccc}
\hline Hari Ke & Ukuran & $\mathrm{Z}$ & MAPE \\
\hline \multirow{3}{*}{1} & $3-\mathrm{Feb}$ & 43,6 & $-0,52$ \\
& $5-\mathrm{Mar}$ & 108,6 & $-0,25$ \\
& $>5$ & 37,7 & $-0,52$ \\
& $3-\mathrm{Feb}$ & 41,1 & $-1,45$ \\
& $5-\mathrm{Mar}$ & 104,7 & 0,08 \\
2 & $>5$ & 34,7 & $-0,74$ \\
& $5-\mathrm{Mar}$ & 107,7 & $-0,06$ \\
& $>5$ & 35,0 & 0,02 \\
$\ldots .$. & $\ldots \ldots$ & $\ldots \ldots$ & $\ldots \ldots$ \\
& $3-\mathrm{Feb}$ & 31,9 & $-21,67$ \\
31 & $5-\mathrm{Mar}$ & 31,3 & $-1,59$ \\
& $>5$ & 109,7 & $-34,30$ \\
\hline
\end{tabular}

Berdasarkan Tabel 15, hasil prediksi kebutuhan ikan selama 1 bulan (November) adalah sebagai berikut:

a. Ukuran $2-3$ ons membutuhkan ikan sebanyak $1290,4 \mathrm{~kg}$

b. Ukuran 3 - 5 ons membutuhkan ikan sebanyak $3346,1 \mathrm{~kg}$

c. Ukuran $\geq 5$ ons membutuhkan ikan sebanyak $1045,5 \mathrm{~kg}$

Selanjutnya, hasil perhitungan MAPE pada predikisi kebutuhan ikan dalam 1 bulan adalah sebagai berikut:

a. Ukuran 2-3 ons, MAPE $=22.2 \%$

b. Ukuran 3 -5 ons, MAPE $=11,9 \%$, dan

c. Ukuran $\geq 5$ ons, MAPE $=22,2 \%$.

\subsection{Pembahasan}

Pada model jaminan mutu ikan, penelitian ini menggunakan 20 data nelayan yang ada di Kecamatan Kota Bangun yang memelihara ikan yang siap di panen pada akhir bulan Desember. Pada model ini menggunakan pendekatan dengan metode Fuzzy Mamdani, hasil yang diperoleh adalah sebagai berikut:

a. Terdapat 8 nelayan yang tidak memenuhi syarat mutu ikan oleh sistem jaminan mutu berdasarkan kriteria agen karena tingkat mutu ikan berada pada tingkat rendah dengan nilai dibawah $40 \%$,

b. Terdapat 9 nelayan yang cukup memenuhi syarat mutu ikan oleh sistem jaminan mutu berdasarkan kriteria agen karena tingkat mutu ikan berada pada tingkat sedang dengan nilai di atas $40 \%$ dan di bawah $65 \%$

c. Terdapat 3 nelayan yang cukup memenuhi syarat mutu ikan oleh sistem jaminan mutu berdasarkan kriteria agen karena tingkat mutu ikan berada pada tingkat bagus dengan nilai di atas atau sama dengan $65 \%$

Pada model prediksi stok ikan yang tersedia, penelitian ini menggunakan 50 data nelayan yang ada di Kecamatan Kota Bangun yang memelihara ikan untuk dijual lagi ke agen. Pada model ini menggunakan pendekatan dengan metode Fuzzy Mamdani dan hasil yang diperoleh adalah sebagai berikut:

a. Terdapat 27 nelayan yang mampu memperoleh hasil panen yang tinggi karena memenuhi semua kriteria yang telah ditentukan. Tingkat hasil panen yang di prediksi berada diatas nilai $60 \%$;

b. Terdapat 13 nelayan yang memperoleh hasil panen sedang karena masih ada kriteria yang belum dipenuhi untuk menghasilkan hasil panen yang tinggi. Tingkat hasil panen yang di prediksi berada diatas nilai $40 \%$ dan dibawah $60 \%$;

c. Terdapat 10 nelayan yang memperoleh hasil panen rendah karena banyaknya kriteria yang belum dipenuhi untuk menghasilkan hasil panen yang tinggi. Tingkat hasil panen yang di prediksi berada dibawah nilai $40 \%$. 
Pada model prediksi kebutuhan ikan yang diperlukan, penelitian ini menggunakan data penjualan agen berdasarkan kriteria berat ikan. Data yang digunakan adalah data penjualan, pembelian, dan persediaan ikan yang ada di agen. Pada model ini menggunakan pendekatan dengan metode Fuzzy Tsukamoto dan hasil yang diperoleh adalah sebagai berikut:

a. Kebutuhan ikan Nila dengan ukuran $2-3$ ons pada bulan November diprediksi paling banyak sebesar 44,9 kg/hari dan prediksi paling sedikit sebesar $31,3 \mathrm{~kg} /$ hari. Jumlah keseluruhan ikan yang diperlukan selama sebulan sebesar 1290,4 $\mathrm{kg} / \mathrm{bulan}$

b. Kebutuhan ikan Nila dengan ukuran 3-5 ons pada bulan November diprediksi paling banyak sebesar $116,3 \mathrm{~kg} / \mathrm{hari}$ dan prediksi paling sedikit sebesar $104,7 \mathrm{~kg} / \mathrm{hari}$. Jumlah keseluruhan ikan yang diperlukan selama sebulan sebesar 3346,1 $\mathrm{kg} /$ bulan

c. Kebutuhan ikan Nila dengan ukuran $\geq 5$ ons pada bulan November diprediksi paling banyak sebesar $37,7 \mathrm{~kg} / \mathrm{hari}$ dan prediksi paling sedikit sebesar $26,8 \mathrm{~kg} /$ hari. Jumlah keseluruhan ikan yang diperlukan selama sebulan sebesar 1045,5 $\mathrm{kg} / \mathrm{bulan}$

d. Hasil perhitungan MAPE pada model predikisi secara keseluruhan dengan nilai CUKUP BAIK.

\section{Kesimpulan}

Model jaminan mutu dan model prediksi ketersediaan dan kebutuhan ikan pada sistem rantai pasok ikan dapat dibuat sesuai dengan kebutuhan dan keinginan konsumen. Penerapan Logika Fuzzy dengan Metode Mamdani dan Tsukamoto secara efektif dapat diterapkan dalam rantai pasok ikan di Kecamatan Kota Bangun agar membantu pihak agen, nelayan, dan retail dalam menjamin mutu ikan dan memprediksi penentuan ketersediaan dan kebutuhan ikan setiap hari.

Berdasarkan data, mutu ikan hanya terdapat 3 nelayan yang memiliki mutu ikan yang bagus dan 9 nelayan yang memiliki mutu ikan yang cukup dan sisanya memiliki mutu ikan yang tidak memenuhi syarat. Pada sistem prediksi stok ikan yang tersedia menghasilkan 27 nelayan diprediksi akan menghasilkan hasil panen yang tinggi, 13 nelayan diprediksi akan menghasilkan hasil panen yang cukup tinggi dan 10 nelayan diprediksi akan menghasilkan hasil panen yang rendah.

Pada model sistem prediksi kebutuhan ikan dengan pendekatan Metode Tsukamoto menghasilkan nilai prediksi yang baik dengan membandingkan nilai prediksi dengan nilai actual, dan berdasarkan nilai MAPE dengan nilai cukup baik.
Berdasarkan hasil perhitungan kebutuhan ikan nila menggunakan Logika Fuzzy Tsukamoto, dapat dikatakan bahwa Penerapan Logika Fuzzy Tsukamoto dapat dipakai sebagai alat peramalan yang baik untuk memprediksi penentuan kebutuhan ikan nila berdasarkan banyaknya permintaan dan persediaan ikan Nila di Kecamatan Kota Bangun.

\section{Daftar Pustaka}

Wang J., Yue H., 2017. Food safety pre-warning system based on data mining for a sustainable food rantai pasok. Food Control 73, 223-229.

Hu J. Y., Zhang J., Mei M., Yang W, Shen Q., 2019. Quality control of a four-echelon agri-food rantai pasok with multiple strategies. Information Processing in Agriculture 6 (4), 425-437.

Wahyuni, I., Mahmudy, W., F., Iriany, A., 2016. Rainfall prediction in Tengger Region Indonesia using Tsukamoto Fuzzy Inference System. 1st International Conference on Information Technology, Information Systems and Electrical Engineering (ICITISEE).

Lambertini, L., 2018. Coordinating research and development efforts for quality improvement along a rantai pasok. European Journal of Operational Research 270 (2), 425-437.

Mohammad, R., Mostafa, A., Abbas, M., Mohammad, R.H., 2015. Prediction of representative deformation modulus of longwall panel roof rock strata using Mamdani fuzzy system. International Journal of Mining Science and Technology 25 (1), $23-30$.

Mojtaba, A., 2016. Optimized Mamdani fuzzy models for predicting the strength of intact rocks and anisotropic rock masses. Journal of Rock Mechanics and Geotechnical Engineering 8 (2), 218-224.

Omomule, T., G., Ajayi, O.O., Orogun, A. O., 2020. Fuzzy prediction and pattern analysis of poultry egg production. Computers and Electronics in Agriculture 171, 105301.

Tri Hastono, Albertus J. S., Pranowo. 2017. Honey Yield Prediction Using Tsukamoto Fuzzy Inference System. Proc. EECSI, 218-224.

Tundo, Enny, I. S., 2018. Application of the fuzzy inference system method to predict the number of weaving fabric production. IJID Int. Journal on Informatics for Development, 7 (1), 21-29.

Yang, W., Yanyan, C., 2014. A comparison of mamdani and sugeno fuzzy inference systems for traffic flow prediction. Journal of Computers 9 (1), 21-29 